Special issue of the 3rd International Conference on Computational and Experimental Science and Engineering (ICCESEN 2016)

\title{
Determining Springback Behavior of High-Strength Steels via Channel Forming Process
}

\author{
E. ESEnER ${ }^{a}$, E. SÖNMEZ ${ }^{a}$, M. ÖZSOY ${ }^{b}$ AND M. FirAT ${ }^{b, *}$ \\ ${ }^{a}$ Bilecik Seyh Edebali University, Mechanical and Manufacturing Engineering Department, Bilecik, Turkey \\ ${ }^{b}$ Sakarya University, Mechanical Engineering Department, Sakarya, Turkey
}

\begin{abstract}
The increasing use of high-strength steels in sheet metal automotive parts usually brings about the springback problems that can not be easily solved, compared to stamping the parts of conventional steel grades. Prediction and compensation of springback at the design stage is very important from both, the academic and the industrial perspectives. For this purpose, finite element analysis and simulative tests are used to understand formability properties of the material. In this study, springback behaviour of high-strength steels was investigated. Angular channel forming process is used as a simulative test with the DP600, DP1000, and DP1400 materials. Channel forming die tools were designed using a shallowly curved geometry for investigating springback behaviour of materials. Die tools were manufactured and forming process was performed at a hydraulic press machine. Sample surfaces were scanned using optical scanning. Then, experimental springback surfaces were compared with reference geometry by shape deviation analysis. It is observed that springback amount of DP1400 is much greater than those of DP600 and DP800 steels. The DP600 steel has minimum springback amount in the flange region and it has shown the smallest deviation from the reference forming surface, as a result of shape deviation analysis.
\end{abstract}

DOI: 10.12693/APhysPolA.132.1010

PACS/topics: 81.20.Hy, 06.60.Mr

\section{Introduction}

Sheet metal forming processes have been widely used in mass production, especially in automotive and related industries. The increasing use of high-strength steels in sheet metal parts, however, brings about the formability and shape distortion problems that can not be easily solved, compared to stamping processes involved with conventional, highly formable steel grades. Today, finite element (FE) simulations are generally used for determination of the process parameters and for modelling material behaviour [1-6]. The process design approaches, based on FE simulation techniques, have experienced similar difficulties with high-strength steel applications and their effectiveness has been questioned, in particular for springback predictions $[7,8]$. Thus, the determination of the amount of springback and making desired compensations at design stage of the stamping processes is important from both, the academic and the industrial perspectives.

Simulative tests are generally used for determining the springback behaviour of materials [9-13]. These tests convert the complex processes into simple bending, forming or cutting problems. $\mathrm{V}$ die bending, U-bending or angular bending tests are some simulative tests, which are commonly used for investigation of the springback behaviour [14-16]. High strength steels show complex springback behaviour, compared to conventional steel grades [17].

*corresponding author; e-mail: firat@sakarya.edu.tr
In this study, it is aimed to determine the springback behavior of higher grades of dual phase (DP) steels. For this purpose, angular channel forming process is used to determine springback behaviour of DP600, DP800, and DP1400 steel grades.

\section{Materials and methods}

Angular channel forming process is used as a forming operation. This simulative test is generally used for determining springback behaviour of materials, due to its shallowly curved geometry. This process takes four die tools, which are the die, the punch, the blank holder, and the sheet metal (blank). Figure 1 shows the die tool surfaces of angular channel forming process. DP600, DP800, and DP1400 steel grades were used as the material under study in experimental investigations. As a first stage of study, the angular channel forming die tools were designed and manufactured (Fig. 2). A CNC vertical machining center was used for die tool manufacturing, and the manufactured die tools were assembled to use in a hydraulic press for forming operations.

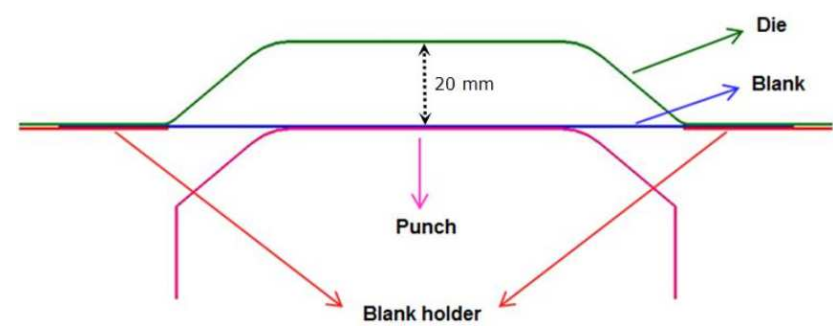

Fig. 1. Die tool surfaces of angular channel forming process. 

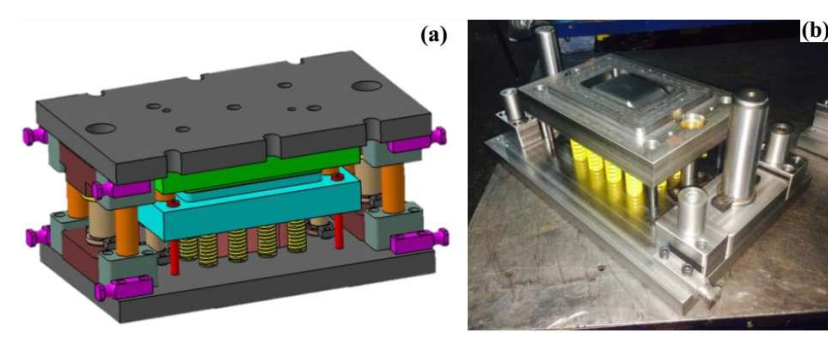

Fig. 2. (a) Die tool design. (b) Manufactured and assembled die tools.

\subsection{Experimental study}

As a first stage of experimental study, sheet metal blanks were cut to a size of $190 \times 40 \mathrm{~mm}^{2}$, by cutting DP600, DP800, and DP1400 sheets with thicknesses of $1.8,3.2$, and $1.2 \mathrm{~mm}$, respectively. Then, blanks were placed between the die tools and the forming operations were performed under the $30 \mathrm{kN}$ blank holder force. Samples are shown in Fig. 3.

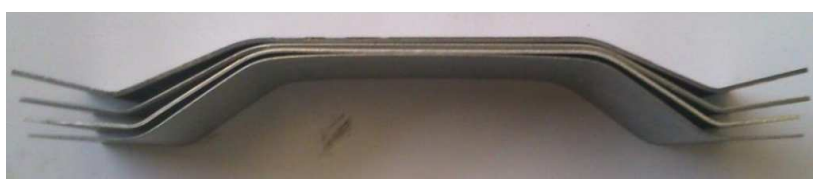

Fig. 3. Samples after forming operation.

\subsection{Shape deviation analysis}

Springback is not the only reason of the shape distortion problems. Die elasticity, rigidity of the press machine, assembly processes or dimension factors cause shape distortion problems. However, it is very difficult to determine these parameters and it is known that the action of springback on shape distortion is more effective then the action of these parameters. Industrial tolerance band is used at comparison of surfaces to eliminate these effects, with the exception of the springback. For this reason, samples were scanned using an optical scanning system for comparison and for determination of the springback behaviour of the materials. Then, springback surfaces were compared with the reference forming surface. 2-D sections of samples are shown in Fig. 4, and an example of the result of shape deviation analysis is shown in Fig. 5 for DP600.

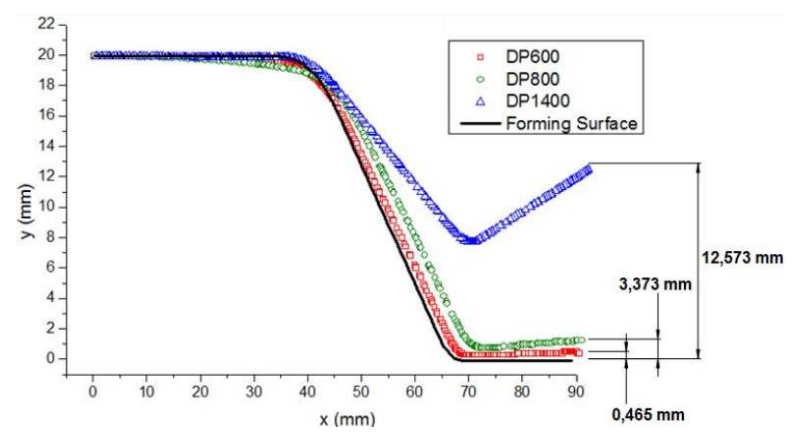

Fig. 4. Comparison of the 2-D section of all samples.

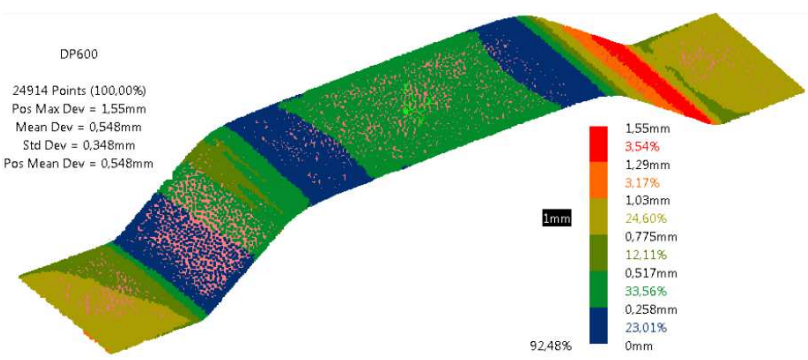

Fig. 5. Shape deviation analysis of DP600 material.

\section{Conclusions}

Results of the shape deviation analysis show that DP1400 has the maximum amount of springback. Maximum springback amount, obtained for DP600, DP800, and DP1400 steels, was $0.47 \mathrm{~mm}, 3.73 \mathrm{~mm}$, and $12.57 \mathrm{~mm}$, respectively. Higher grades of DP steels have shown a more complex springback behaviour. The results of shape deviation analysis for all materials are shown in Table I.

TABLE I

Results of shape deviation analysis for all investigated materials.

\begin{tabular}{c|c|c}
\hline \hline Material & $\begin{array}{c}\text { Shape deviation } \\
{[\%]}\end{array}$ & $\begin{array}{c}\text { Maximum springback } \\
{[\mathrm{mm}]}\end{array}$ \\
\hline DP600 & 92.48 & 0.465 \\
DP800 & 62.88 & 3.373 \\
DP1400 & 46.08 & 12.573
\end{tabular}

\section{References}

[1] Ö. Karaçalı, Acta Phys. Pol. A 128, B-40 (2015).

[2] M. Urbanek, D. Blaszkiewicz, Acta Phys. Pol. A 128, B-241 (2015).

[3] E. Kanca, F. Çavdar, M.M. Erşen, Acta Phys. Pol. A 130, 365 (2016).

[4] W. Kilpatrick, D. Brown, A.G. Leacock, Int. J. Mech. Sci. 101, 363 (2015).

[5] T. Clausmeyer, A. Güner, A.E. Tekkaya, V. Levkovitch, B. Svendsen, Int. J. Plasticity 63, 64 (2014).

[6] R. Azizi, Mater. Design 30, 2975 (2009).

[7] K.P. Li, W.P. Carden, R.H. Wagoner, Int. J. Mech. Sci. 44, 103 (2002).

[8] Automotive Steel Design Manual, Auto/Steel Partnership \& American Iron and Steel Institute, Southfield, Michigan, USA 2002.

[9] M. Samuel, J. Mater. Proc. Technol. 105, 382 (2000).

[10] D.-K. Leu, Mater. Design 94, 314 (2016).

[11] O. Tekarslan, U. Seker, A. Ozdemir, Mater. Design 27, 251 (2006).

[12] F. Ozturk, S. Toros, S. Kilic, J. Iron Steel Res. Int. 16, 41 (2009). 
[13] M. Firat, Mater. Design 28, 1298 (2007).

[14] O. Tekarslan, N. Gerger, U. Seker, Mater. Design 29, 1043 (2008).

[15] M. Firat, B. Kaftanoglu, O. Eser, J. Mater. Proc. Technol. 196, 135 (2008).
[16] A.P. Karafillis, M.C. Boyce, Int. J. Mach. Tools Manufact. 36, 503 (1996).

[17] G. Ingarao, R. Di Lorenzo, F. Micari, Mater. Design 30, 4421 (2009). 